3 Van Rood JJ, Gernisse JG, Van Leeuwen A. Leucocyte antibodies in sera from pregnant women. Nature 1958; 181 :1735-6.

4 Payne R, Rolfs MR. Fetomaternal leukocyte incompatibility. J Clin Invest 1958;37:1756-8.

5 Opelz G, Terasaki PI. Studies on the strength of HLA antigens in related donor kidney transplants. Transplantation 1977:24:106-11.

6 Simmons RL, Van Hook EJ, Yunis EJ, et al. 100 sibling kidney transplants followed 2 to $7 \frac{1}{2}$ years. A multifactorial analysis. Ann Surg 1977;185:196-204.

7 Histocompatibility testing. Los Angeles: UCLA Press, 1980.

8 Ting A, Morris PJ. Powerful effect of HLA-DR matching on survival of cadaveric renal allografts. Lancet 1980;ii: 282-5.

9 Van Rood JJ, Persijn GG, Lansbergen Q, et al. How can HLA matching improve kidney graft survival? Proc Eur Dial Transplant Assoc 1979;16:297-304.

10 Dick H. Histocompatibility, 1980. Immunology Today 1980;1:1-7.

Requests for reprints to Dr G R D Catto, Department of Medicine, University of Aberdeen, Foresterhill, Aberdeen AB9 2ZD.

\section{Cherchez les femmes (or the personal touch in the laboratory)}

A recent development in the prenatal diagnosis of neural tube defects has been the discovery that the qualitative assay of amniotic fluid cholinesterase and acetylcholinesterase (AChE) may be an even better diagnostic tool than $\alpha$-fetoprotein. ${ }^{1}$

In the course of evaluating this new development, I (M) and my collaborators ( $K$ and $B$ ) encountered a problem. The method ${ }^{2-4}$ is relatively simple, consisting of protein separation by polyacrylamide gel 'disc' electrophoresis and then enzyme localisation by incubation in enzyme substrate. Initially, the method worked successfully in this laboratory without even any teething problems, and a whole study was completed by two of us $(\mathrm{M} \text { and } \mathrm{K})^{5}$ on the AChE of a large number of normal and abnormal amniotic fluids. But when subsequently the method was introduced into our routine diagnostic programme, the third person (B) could not make it work. B is a competent and clever technician and she did not appear to be doing anything wrong. Thus it was decided that some experiments must be performed in order to determine the cause of the failure.

\section{EXPERIMENT 1}

Hypothesis. That, since B works in a large open laboratory which is colder than the small rooms where $\mathrm{M}$ and $\mathrm{K}$ work, the lower ambient temperature

Received for publication 18 November 1980 was inhibiting enzyme activity. B performed the enzyme assay in K's room. Result: failure.

\section{EXPERIMENT 2}

Hypothesis. That the $\mathrm{pH}$ of one of the solutions used in the method was wrong. B checked the $\mathrm{pH}$ of all solutions before performing the assay. Result: failure.

\section{EXPERIMENT 3}

Hypothesis. That the potency of the enzyme substrate had diminished through prolonged use of the batch. B doubled the amount of substrate used. Result: failure.

\section{EXPERIMENT 4}

Hypothesis. That the batch of enzyme substrate in use had 'gone off' completely. B bought and used a new batch of substrate. Result: failure.

\section{EXPERIMENT 5}

Hypothesis. That this second batch of enzyme substrate, by an unfortunate coincidence, was also faulty. B obtained from another laboratory, and used, an aliquot of enzyme substrate known to be working. Result : failure.

\section{EXPERIMENT 6}

Hypothesis. That one of the other chemicals in use in the procedure was faulty. B bought and used a complete set of new chemicals. Result: failure.

\section{EXPERIMENT 7}

Hypothesis. That new plastic tubes used for the incubation step were inhibiting the enzyme. B changed to glass tubes. Result: failure.

\section{EXPERIMENT 8}

No hypothesis, just desperation. M performed the whole technique without trying particularly hard. Result: success.

A more detailed scientific investigation was obviously necessary.

The procedure can be broken down basically into three steps: (1) preparation of the solutions, (2) gel making and the electrophoresis, and (3) enzyme localisation.

\section{EXPERIMENT 9}

M did steps 1 and 3, B did step 2. Result: success. Conclusion: $B$ had no problem with gel making and electrophoresis.

\section{EXPERIMENT 10}

B did step 1, M did steps 2 and 3. Result: success. Conclusion: $B$ had no problem with preparation of solutions.

It appeared, therefore, that the error was occurring 
in the enzyme localisation step. This was confirmed by the next two experiments.

\section{EXPERIMENT 11}

$M$ did steps 1 and 2 with duplicate tubes; for step 3, B took one set of tubes. Result: failure. $M$ took the other set. Result: success.

\section{EXPERIMENT 12}

B did steps 1 and 2 with duplicate tubes; for step 3, $M$ took one set of tubes. Result: success. B took the other set. Result: failure.

This problematical step 3 may, in turn, be divided into two component processes: (3a) preparation of incubation solution, and (3b) removal of gels from the electrophoresis tubes and addition of gels to the incubation solution.

\section{EXPERIMENT 13}

$M$ did steps 1 and 2 in duplicate and 3a. At step $3 b$, $M$ took one set of tubes. Result: success. B took the other set. Result: failure. Conclusion: the error was occurring as $B$ removed the gels from the tubes and added them to the incubation solution.

$M$ and B carefully examined each other's method for step 3b. Yet again, no difference in procedure was observed. Suddenly, however, a minor difference was noted: B wore disposable gloves and $\mathbf{M}$ did not.

\section{EXPERIMENT 14}

$M$ performed in duplicate steps 1 and 2 and, on one set of tubes, steps $3 \mathrm{a}$ and $3 \mathrm{~b}$ as usual. Result: success. $B$ performed steps $3 \mathrm{a}$ and $3 \mathrm{~b}$ without wearing gloves. Result : success. Conclusion: Eureka!

However, we could not overlook the fact that $\mathrm{K}$ also wore gloves when she did the procedure. We were forced to account for this observation.

Both $\mathrm{B}$ and $\mathrm{K}$ are very good workers but there is a subtle difference between them. $K$ never throws anything away and uses the same pair of disposable gloves for weeks on end, while B is painstakingly cautious and sometimes uses even two new pairs of gloves during the course of the same experiment.

$K$ then recalled that once when she was demonstrating the technique to visitors, she thought it best to do everything in exemplary fashion, so she took new gloves, and the technique had not worked, her only failure ever.

We examined the gloves (Triflex medical disposable gloves, Travenol Laboratories) and observed that they have on their outer surface a fine white powder.

\section{EXPERIMENT 15}

Method. A pair of Triflex gloves was washed in running tap water for one hour, left soaking in distilled water overnight, and then dried. B performed steps 1 and 2 in duplicate and then steps $3 \mathrm{a}$ and $3 \mathrm{~b}$ on one set of tubes using no gloves. Result: success. For the other set of tubes, steps $3 a$ and $3 b$ were performed using the thoroughly washed gloves. Result: success.

From that moment on, B has had no trouble with the technique. It had taken one month to isolate and identify the cause of the problem, which was resolved in this most unexpected way. Travenol Laboratories inform us that their gloves are covered with a lubricant composed of maize starch powder. The mechanism of enzyme inhibition by this substance has not been investigated.

I acknowledge with admiration and gratitude the hard work and unflagging spirit of B (Miss Bernadette Merritt) and the advice and co-operation of K (Mrs Kathleen Cole).

MARY J SELLEt
Paediatric Research Unit
The Prince Philip Research Laboratorie
Guy's Hospital Medical School, London SE1 $9 R T$

\section{References}

1 Leader. Amniotic fluid acetylcholinesterase. Lancet $1980 ;$ ii: $407-8$.

2 Clarke JT. Simplified "disc" (polyacrylamide gel) electrophoresis. Ann NY Acad Sci 1964;121:428-36.

3 Chubb IW, Smith AD. Isozymes of soluble and membrane-bound acetylcholinesterase in bovine splanchnic nerve and adrenal medulla. Proc $R$ Soc Lond (Biol) $1975 ; 191: 245-61$.

4 Smith AD, Wald NJ, Cuckle HS, Stirrat GM, Bobrow M, Lagercrantz H. Amniotic fluid acetylcholinesterase as a possible diagnostic test for neural tube defects in early pregnancy. Lancet $1979 ; \mathbf{i}: 685-8$.

5 Seller MJ, Cole KJ. Polyacrylamide gel electrophoresis of amniotic fluid cholinesterases: a good pre-natal test for $I$ neural tube defects. Br J Obstet Gynaecol 1980;87:1103-8.

Requests for reprints to Dr M J Seller, Paediatric N Research Unit, The Prince Philip Research Labora- N tories, Guy's Hospital Medical School, London N SE1 9RT. 